\title{
LAS RELACIONES ENTRE EL PODER ECLESIASTICO Y EL PODER POLÍTICO LOS CASOS DE ALBERTO MAGNO, TOMÁS DE AQUINO, JUAN QUIDORT, MARSILIO DE PADUA Y ALVARO PELAGIO
}

\author{
José Ricardo Pierpauli
}

CONICET

\begin{abstract}
This comparative study will reveal the true cause of discrepancies that surrounding the issue of relations between the ecclesiastical power and the political, is due to the breakdown of the Aristotelian neo-platónico synthesis produced by Albert the great and received by his disciple Thomas Aquinas during the first half of the 13th century. Instead, the conjuncture solutions offered from the second half of the that same century gave rise to what would later call the modern State. A comparative study of the political philosophy that includes contributions offered during the middle ages may even offer solutions to certain problems of the current political philosophy.
\end{abstract}

Keywords: Ordo naturae, power, common good, neoplatonism, aristotelianism.

Resumo: El presente estudio comparativo se propone poner de manifiesto que la verdadera causa de las discrepancias que, en torno de la cuestión de las relaciones entre el poder eclesiástico y el político, se debe a la ruptura de la síntesis neo-platónico aristotélica elaborada por Alberto Magno y recibida por su discípulo Tomás de Aquino durante la primera mitad del siglo XIII. En cambio, las soluciones de coyuntura ofrecidas a partir de la segunda mitad del ese mismo siglo dieron origen a lo que más tarde se denominaría el Estado moderno. Un estudio comparativo de la Filosofía Política que incluya los aportes ofrecidos durante la Edad Media puede aun ofrecer soluciones a determinados problemas de la Filosofía Política actual.

Palabras clave: Ordo naturae, poder, Bien común, Neo-Platonismo, Aristotelismo. 


\section{Introducción}

El título del presente trabajo alude a la contribución de la Filosofía Política Medieval respecto de algunos de los actuales problemas de la Filosofía Política. Pero precisamente aquí se nos presenta la primera y tal vez la mayor dificultad: Existe una Filosofia Política con límites claramente definidos en la Edad Media? Una cosa es admitir que dentro del período medieval ocurrieron hechos dignos de ser conservados en el museo de las ideas políticas y otra bien diferente es postular la existencia de tesis filosóficas a partir de las cuales aun hoy podemos extraer soluciones ante nuevos problemas. Contra la opinión vulgar, que por otra parte no es otra cosa que el resultado último de la sustitución de la Filosofía por las ideologías, debe decirse que de hecho existe una Filosofía Política como la que pretendemos exponer aquí.

La estructura interna de esa Filosofía está dada por la traducción del orden de la Creación según la medida y las posibilidades de la inteligencia humana. A partir de lo dicho hasta aquí debemos resolver un nuevo interrogante: De existir una Filosofía Política propia de la Edad Media, en qué medida es lícito llamarla cristiana, habida cuenta que ese período histórico-filosófico se caracterizó por la recepción y transformación de las tradiciones griega y romana a la luz de las teologías que se articularon a partir de la idea de revelación que sustentaron los árabes, los cristianos y los judíos? Si por Filosofía entendemos el amor por la sabiduría a través del asombro ante la existencia de las cosas, si esas cosas que son capaces de asombrarnos y a las que percibimos primariamente mediante los sentidos exteriores y luego mediante la inteligencia, suscitan en nosotros el deseo por alcanzar lo humanamente ininteligible, entonces debe decirse no solo que debemos llamar cristiana por derecho propio a la Filosofía de la Edad Media, sino que se trata de la libre actividad de la razón humana a la luz de la recepción de la Teología Cristiana.

La reflexión filosófica a que nos referimos parte de la realidad. Allí comienza el camino de la razón, mas se extiende hasta lo verdaderamente universal donde reposa el fundamento último de la verdad. De este modo el amor por la sabiduría del que hablaban los antiguos, experimentó una auténtica transformación en la Edad Media. En efecto, sabiduría es ahora el 
saber acerca de lo más alto. Más aun, por ese mismo motivo la razón se constituyó paradójicamente en sierva de la Teología Sobrenatural alcanzando allí la verdadera medida de su perfección.

Así pues, la razón se puso al servicio de la Fe y entre ambos niveles quedó trazado el eje sistemático que daría sentido a las grandes elaboraciones producidas en especial durante el siglo XIII. Por este motivo nuestro análisis no podrá ser puramente histórico político, sino filosófico según la idea de Filosofía que se ha intentado bosquejar rápidamente hasta aquí.

Ahora bien, el problema de la relaciones entre el poder eclesiástico y el poder político constituye un nuevo modo de plantear el problema antes enunciado a saber, el de las relaciones entre Razón y Fe, entre Filosofía y Teología. "La Ciencia Política auténtica como saber práctico no es radicalmente autónoma respecto de la Teología Sobrenatural.” No hay, en los casos de los autores que nos ocupan, un Dios para los filósofos y otro para los creyentes. Lo que diferencia las posiciones de esos autores es el tipo de relaciones que mantienen los creyentes con Dios. El Bien del que parten los filósofos recibe su contenido esencial de la Teología y se traslada hacia el interior de todas nuestras conclusiones prácticas. No hay una autonomía de la moral ni de la política respecto de las verdades que postula la Teología. Ningún autor serio olvidó los argumentos teológicos al formular sus propias tesis filosófico-políticas. Ello debido a que la Teología Sobrenatural constituye en cierta medida, un saber práctico al igual que la Ciencia Política ${ }^{1}$. Hay pues dos modos de plantear el problema de las relaciones entre el Poder Eclesiástico y el Político, a saber, dentro de los límites del Medioevo y fuera del mismo, dentro de la Modernidad. Entendemos por modernidad aquel período de la Historia de la Filosofía caracterizado por el esfuerzo por liberar la inteligencia humana de toda instancia superior.

Pero, aun permaneciendo dentro del ámbito de la Edad Media, lo que aquí debemos discutir no es tan solo la estructura interna de las argumentaciones filosófico-políticas, sino también las circunstancias en las que determinadas filosofías políticas nacieron. Mientras Alberto Magno y su discípulo Tomás de Aquino escribieron sus respectivas filosofías políticas como lógica derivación de sus sistemas, algunos discípulos de Tomás tales como Juan Quidort, Dante y, más allá de ese círculo, el propio Marsilio de

${ }^{1}$ Cfr. SANCTI THOMAE DE AQUINO, Summa theologiae, I pars, Q. I, art. 4, ed. San Paolo, Torino, 1988, pags. 5-6 
Padua debieron elaborar las suyas como respuesta a un problema político determinado, como fue la controversia entre el Papado y el Imperio en tiempos de Felipe el Hermoso y Bonifacio VIII. Esa relación entre el Papado y el Imperio no era tan problemática en tiempos de Alberto y de Tomás como lo sería más tarde.

Alberto Magno y Tomás de Aquino inscribieron sus Filosofías Políticas en el interior de un orden trascendente que reconocía a Dios como alfa y omega. En cambio Marsilio, un verdadero precursor de la modernidad, separó la Política del interior de ese sistema para formular una nueva Teología adaptada según la medida y las pretensiones de autonomía del Imperio respecto del Papado. Como más tarde ocurriría, la separación del poder político respecto de la Teología no fue pacífica, sino que implicó una nueva y dura crítica contra las autoridades religiosas que defendían el primado de la Teología y de la Fe. La subordinación de la Teología a la Política propuesta por Marsilio dejaría pues sentadas las bases para la constitución del Estado totalitario. Así pues, nuevamente la lógica de esta argumentación nos obliga a optar entre dos modos diferentes de tratar la cuestión de las relaciones entre ambos poderes. O bien se resuelve desde el punto de vista puramente histórico, o bien desde el punto de vista filosófico. La opción por este segundo modo, a saber el filosófico, nos permitirá rehabilitar la dimensión trascendente del orden político. La idea central que pretende ofrecerse a través del presente estudio podría resumirse de este modo: Desde el punto de vista estrictamente filosófico-político la cuestión de las relaciones entre el poder eclesiástico y el civil debe remitirse al ámbito de las relaciones entre fe y razón y, a su vez, esta importante cuestión experimentó significativas variaciones según que se las examine desde el punto de vista de la integración neo-platónico arisototélica elaborada por Alberto Magno, o bien desde la ruptura de dicha síntesis, operada principalmente a partir de la segunda mitad del siglo XIII. Es allí donde tubo lugar aquello que podríamos llamar el nacimiento del Estado Moderno.

1. El problema de las relaciones entre el poder eclesiástico y el político constituye un modo de concreción de las relaciones entre Fe y Razón. La recepción de la Política de Aristóteles a la luz del modelo neo-platónico, aristotélico de Alberto Magno.

"Nulla potestas nisi a Deo". El texto bíblico ofrece un claro contenido político pero al mismo tiempo abre un sinnúmero de dificultades que hasta 
hoy dividen a los filósofos políticos. Veamos cuales son las conclusiones que a partir del ese texto pueden extraerse. Si todo poder viene de Dios, resta saber si: 1- el poder es concedido por Dios directamente, o bien 2- por intermedio de alguna otra instancia. En esta segunda perspectiva, o bien esa segunda instancia es la autoridad religiosa, en nuestro caso el Papa, o el gobernante político como representante del consenso del pueblo.

Ciertamente permaneceríamos perplejos si, en el intento por defender la primera tesis enunciada en primer lugar, esto es que literalmente todo poder viene de Dios, omitiéramos la importante contribución ofrecida por Aristóteles en el libro I de su Política. Allí el Estagirita muestra el valor insoslayable que adquiere la naturaleza entendida como orden pre-político ${ }^{2}$. Sin duda, los autores han recurrido a otros pasajes bíblicos para fundamentar sus respectivas posiciones a favor de una u otra de las variantes enunciadas, mas creemos que el texto aquí propuesto, junto a la idea de naturaleza entendida como orden nos conducirá directamente hacia la recuperación de la medida trascendente del orden político y, naturalmente, a una mejor comprensión de la verdadera respuesta frente al problema de las relaciones entre la Iglesia y el Estado. En efecto la idea de servi a natura constituye la médula de la argumentación aristotélica cuando se pretende fundamentar la formación jerárquica y natural de la Comunidad Política tal como lo hace el Filósofo en su primer libro de la Política. A su vez, La unión del aporte filosófico-político recogido de la tradición neo-platónica que Alberto Magno recibe, junto con la tradición aristotélica que acabo de mencionar, permite arribar a la siguiente solución provisoria: "Todo poder viene directamente de Dios y se expresa a través de la naturaleza humana entendida como ordo naturae."

Alberto mismo une armónicamente estos dos momentos. En efecto, dentro de un contexto teológico como es la "Suma de creaturis, De homini", defenderá la siguiente tesis:

“[...] Sicut dicit Dionysius, quod Deus omnibus aequaliter adest, sed non omnia sibi aequaliter adsunt: eo quod non aequailter bonitates suas participant seu percipiunt. Bonitates autem suae sunt, esse, et vivere, et cognitio sensibilium et intelligibilium: et entia quae plura de his percipiunt et

\footnotetext{
2 Cfr. ONCKEN W., Die Staatslehre des Aristoteles in historisch-politischen Umrissen. Ein Beitrag zur Geschichte der hellenischen Staatsidee und zur Einführung in die aristotelische Politik. Aalen, 1964, pags. 12-13
} 
nobiliori modo sunt ei propinquora: quia vero propincuora et modo minus nobili, sunt remotiora per convenientiam essentiae, ut existentiam tantum in ultimo gradu, existentia autem vita et cognitiva et inmortalia in primo, existentia autem et viva et sentientia rationabilia mortalia in mediis gradibus[... $]^{3} . "$

Alberto defiende la idea siguiente, a partir de la efusión de la Bondad Divina puede leerse en la naturaleza un cierto orden, lo que en términos filosófico-políticos quiere decir, una cierta jerarquía implícita ${ }^{4}$. Una idea semejante defiende Aristóteles ${ }^{5}$ cuando sostiene que es del orden de la naturaleza que los bárbaros se sometan a los cultos. Hay hombres que están dotados solo para las actividades rústicas, pero que no son capaces de formular sus propias normas de conducta. En cambio, hay otros hombres que son menos capaces para las tareas rústicas por la complexión de su cuerpo, pero, en virtud de las disposiciones de su inteligencia, son aptos no solo para gobernarse a sí mismos, sino también para prescribir normas de conducta adecuadas para sus semejantes. Por su parte Alberto recoge sus tesis neo-platónicas unidas a las tesis de Al-farabi y dice al comienzo de su Comentario a la Política: "non est mortuus, qui scientiam vivificavit: nec fuit pauper, qui intellectui dominatus est, sive qui intellectum possedit ${ }^{6}$ ". A diferencia de Al-farabi quien al formular sus tesis políticas en su "Musterstaat y en On the perfect stat", recae en un intelectualismo filosófico-político, Alberto agrega que el punto de partida y la más alta medida de la Filosofía Política solo se adquiere cuando el intelecto adquirido (adeptus) alcanza su máxima perfección mediante el conocimiento de la Justicia Divina. "Nosse te est consummata iustitia, et scire iustitiam tuam et virtutem tuam radix est immortalitatis" (Sap. XV). "Hinc est, quod dicit Alfarabius in libro De intellectu et intelligibili, quod, omnes philosophi in intellectu adepto divino radicem posuerunt immortalitatis animae" $\mathrm{Al}$ punto de vista teorético esbozado por Al-farabi une aquí Alberto el momento práctico.

\footnotetext{
${ }^{3}$ ALBERTUS MAGNUS, De homine, Ed. París, París, 1896, p. 661.

${ }^{4}$ Cfr. VOEGELIN E., The Collected Works of Eric Voegelin, Vol. 19, History of Political Ideas. Hellenism, Rome, and early Christianity, London, 1997, pag. 170

${ }^{5}$ Cfr. ARISTOTELES, Política, 1252 b 5

${ }^{6}$ ALBERTUS MAGNUS, Politicorum libri VIII, ed. París, París, 1891, pag. 6

7 Cfr. ALBERTUS MAGNUS, Summa theologiae sive mirabile scientia Dei, ed. Colon, Munster, 1978, pags. 1-2
} 
Para Alberto Dios ha creado todas las cosas según tres dimensiones, "modo, forma y orden." Al texto nulla potestas nisi a Deo podría agregarse ahora "nulla potestas nisi a Deo ordenans." El orden de la Naturaleza se expresa en la naturaleza humana principalmente mediante la subordinación de todas las potencias humanas al gobierno de la inteligencia. Una vez que Dios lo ha creado todo, comenzó a ejercer el gobierno de Su Creación, según el orden por el mismo establecido. Aquí Alberto recurre a un argumento de origen platónico, a fin de sentar las bases tanto de sus ideas acera de la relación entre el Poder Eclesiástico y el Político, como aquellas otras que permiten resolver el problema de las formas de gobierno político. "Dice el doctor universalis:”

"Nulla potestas una aequaliter potest esse immediata multis, ita quod aequa sit virtus eius et providentia in omnibus, ideo oportet ipsam habere particulares potestates, quae prospiciant inferioribus. Sic enim motor orbium habet particulares motores sphaerarum, sic anima in corpore particulares habet vires membrorum, et sic est in omnibus aliis videre Albertus Magnus, Super Matthaeum ${ }^{8}$ ".

Dios ha creado pues una totalidad con leyes propias. Esa totalidad se gobierna a través del concurso de las criaturas inferiores. Se verá más adelante la relevancia de estas conclusiones parciales los fines de la solución que buscamos.

2. La razón humana se eleva hasta sus propios límites incluso sobrepasándolos, a través de los indicios que le ofrece la naturaleza. El modelo filosófico político de Tomás de Aquino. El acabamiento de la síntesis neo-platónica y aristotélica elaborada por Alberto Magno

Tomás alude explícitamente a las relaciones entre ambos poderes en dos lugares de su obra. Mas sus referencias pueden entenderse aun mejor a partir de la doctrina de Alberto Magno hasta aquí ofrecida. Esos lugares son:

\footnotetext{
8 "Dado que ninguna potestad puede estar inmediatamente presente en todas las cosas de modo tal que su virtualidad sea efectiva a fin de adoptar las providencias en todas las circunstancias, conviene que aquella potestad disponga de potestades particulares que atiendan los casos menores. En efecto, así como el motor del orbe tiene a su vez motores para mover las esferas inferiores, así mismo el alma humana que vivifica al cuerpo, dispone de fuerzas que mueven los miembros del cuerpo. Así pues en todas las cosas" ALBERTUS MAGNUS, Super Matthaeum, Ed. Colon., Münster, pag. 193-30/37
} 
en su Comentario a las Sentencias de Pedro Lombardo, II, 44 y en el De regno. El Aquinate igual que su maestro, privilegia la cuestión del origen del poder, mas no apoyándose solo en el texto bíblico, sino como su maestro, en las tradiciones filosóficas preexistentes. En efecto, ya en las primeras líneas del De regno Tomás recurre a la doctrina de la participación de la inteligencia igual que lo había hecho Alberto. "Hominis autem est aliquis finis ad quem tota eius vita et actio ordinatur, cum sit agens per intellectum cuius est manifeste propter operari. Contingit autem diversimode homines ad finem intendum pocedere, quod ipsa dicersitas humanorum studiorum et actionum declarat; indiget igitur homo aliquo dirigente ad finem ${ }^{9}$.” Aquí, en plena coincidencia con lo dicho por Aristóteles en la Política 1252 a 1, Tomás alude a la natural constitución de la comunidad política y a la necesidad de un gobernante que la conduzca hacia su fin propio.

El texto queda subordinado a la referencias que en De regno realiza Tomás respecto de la obra creadora de Dios. Dios ha creado las cosas según dos momentos, en primer lugar, las ha creado en su existencia y, en segundo momento, las dotó de lo necesario para alcanzar su fin propio. Así por tanto debe obrar el hombre.

\begin{abstract}
"Sunt autem universaliter consideranda duo opera Dei in mundo: unum quo mundum instituit, alterum quo mundum institutum gubernat. Haec etiam duo opera anima habet in hábeas: nam primo quidem virtute formatur hábeas, deinde vero per animam hábeas regitur et movetur. Horum autem secundum quidem magis propie pertinet ad regis officium, unde ad omnes reges pertinet gubernatio, et a gubernationis regis nomen accipitur ${ }^{10}$."
\end{abstract}

Tomás justifica de este modo la necesidad de un poder que gobierne. El Aquinate une a la observación de la naturaleza como orden, el momento teológico que ya su maestro Alberto Magno había combinado también con la tradición aristotélica. LuegoVeamos de qué modo subordina su argumentación filosófica a la teológica: "Oportet igitur considerare quid Deus in mundo faciat, sic enim manifestum erit quid immineat regi faciendum.... Ratio autem institutionis regni ab exemplo institutionis mundi

\footnotetext{
9 TOMAS DE AQUINO, De regno, I-1, Ed. Leon, Roma1979, pag. 459-10 y sgts.

10 TOMAS DE AQUINO, De regno, pag. $464-5$ y sgts.
} 
sumendua est: in quo primo consideratur ipsarum rerum productio, deinde partium mundi ordinata distinctio ${ }^{11}$." Ahora bien, una vez pues que hemos reconstruido el marco teórico, nos ocuparemos de sus consecuencias en orden al problema de las relaciones entre el poder eclesiástico y el político. En este contexto, El Doctor angélico alude concretamente a las relaciones del Papa y del Emperador como conclusión de lo dicho anteriormente.

“[...] et praecipue summo sacerdote sucessori Petri, Christi vicario Romano Pontifici, cui omnes regis populi Christiani oportet esse subiectos sicut ipsi Domino Ihesu Christi. Sic enim, ut dictum est, ei ad quem ultimi finis pertinet cura subid debent illi ad quos pertinet cura antecedentium finium, et eius imperio dirigi. Quia igitur sacerdotium Pentium et Aotus divinorum cultus erat propter temporalia bona conquirenda, que omnia ordinantur ad multitudinis bonum commune cuius regi cura incumbit, cxonvenienter sacerdotes gentilium regibus subdebantur. Sed et in Viteri lege promittebantur bona terrena, non a demonibus sed a Deo vero, religioso populo exhibenda; unde et in Viteri lege sacerdotes regibus leguntur fuiste subiecti. Sed in Nova lege est sacerdotium altius, per quod homines traducuntur ad bona celestia; unde in lege Christi reges debent sacerdotibus esse subiecti12."

Como fue dicho, la argumentación del Aquinate parte de un fundamento teológico y de otro filosófico. El fundamento filosófico está constituido por los siguientes elementos: 1-Las doctrinas políticas de

\footnotetext{
11 ibidem

12 "Al romano pontífice todos los reyes humanos del pueblo cristiano han de estar sujetos como a Nuestro Señor Jesucristo mismo. Por que aquellos a quienes concierne el cuidado de los fines intermedios deben estar sujetos a aquél a quien concierne el cuidado del fin último, debiendo regirse por éste. Y ya que el sacerdocio de los gentiles y de todo el culto de sus dioses existía meramente para la adquisición de bienes temporales ( los estaban todos ordenados al bien común de la multitud, cuyo cuidado recaía sobre el rey), los sacerdotes de los gentiles estaban muy apropiadamente sujetos a los reyes. Similarmente, puesto que en la antigua ley los bienes terrenos estaban prometidos al pueblo religioso (no en verdad por los demonios, sino por el verdadero Dios), leemos que los sacerdotes de la antigua ley estaban también sometidos a los reyes. Pero en la nueva ley hay un sacerdocio superior por el cual los hombres son dirigidos el bien celestial. Consecuentemente, en la ley de Cristo, los reyes deben estar sujetos a los sacerdotes." TOMAS DE AQUINO, De regno, II-14 pag. 466-113
} 
Aristóteles, 2-La recepción de la doctrina política organológica ${ }^{13}$ de Platón a través de su maestro Alberto Magno y 3-el neo-platonismo también recibido de su maestro especialmente en su paso por la ciudad de Colonia. El fundamento teológico por su parte está dado por la diferencia, también presente en Quidort, entre el sacerdocio de la antigua ley y el de la nueva ley. En el Comentario a las Sentencias alude nuevamente al problema de las relaciones entre ambos poderes, a la luz de su concepción total del orden natural y del sobrenatural.

"[...]Potestas spiritualis et saecularis, utraque deducitur a potestate divina, et ideo intantum saecularis potestas est sub spiritualis, inquantum este i a Deo supposita, scilicet in his quae ad salutem animae pertinent; et ideo in his magis est obediendum potestati spirituali quam saeculari. In his autem quae ad bonum civile pertinent, est magis obediendum potestati saeculari quam spirituali, secundum illud Matth. 2221: Reddite quae sunt Caesari. Nisi forte potestati spirituali etiam saecularis potestas enjungantur, sicut Papa, qui utriusque potestatis apicem tenet, scilicet spiritualis et saecularis...14."

He colocado en segundo lugar aquello que está primero en el orden cronológico, pues a los fines de nuestra exposición era necesario. Mas ahora deben aclararse algunas cuestiones. El texto de Tomás en De regno no es diferente en cuanto a su doctrina, del propuesto en el Comentario a las Sentencias, tal como se ha creído. Tomás no discute aquí, como más tarde lo harán algunos de sus discípulos, si el Papa debe o no tener ingerencia en las cuestiones políticas. Tampoco afirma que la subordinación integral del poder político al eclesiástico en la figura del Papa y los sacerdotes implique la

${ }^{13}$ Cfr. STRUVE T., Die Entwicklung der organologischen Staatsauffassung im Mittelalter, Stuutgart, 1978, pags. $149-165$

14 "El poder espiritual y el secular proceden del poder divino. Por ello, el poder secular está subordinado al espiritual en aquellas cuestiones con respecto a las cuales la subordinación ha sido especificada y ordenada por Dios, es decir, en cuestiones que se refieren a la salvación del alma. En éstas, nosotros tenemos que obedecer a la autoridad espiritual más que a la secular. Por otra parte, se debe más obediencia al poder secular que al espiritual en las cosas que se refieren al bien político. Por que se dice en Mt. 22,21: Dad al César lo que es del César. Un caso especial ocurre, sin embargo, cuando el poder espiritual y secular se encuentran unidos en una persona, como lo están en el Papa, que se encuentra en la cumbre, tanto del poder espiritual como del secular..."THOMAE AQUINATIS, In II Sent., Dist. 44, ed. Parmae, New York, 1948, pags. 790-791 
disminución de la potestad política. Aun cuando el Papa esté en la cumbre de la pirámide del orden eclesiástico y del político, no puede estar presente en todos lados ni en todas las cuestiones, por ese motivo el emperador y demás potestades políticas son como ministros suyos, claro está, en la perspectiva última de la economía de la salvación de las almas. Sin la consideración de la influencia neo-platónica integrada al aristotelismo político tal como lo hizo Alberto Magno, ambos textos de Tomás aparecen como contradictorios. No se trata de las preferencias de Tomás a favor de la posición de los güelfos o de los gibelinos, sino de la lógica interna de sus tesis. No hay una tajante separación entre la esfera de la naturaleza y la de la gracia, pues gratia non destruit naturam, sed perficiat eam. De aquí la importancia de comprender al Aquinate a la luz de las doctrinas de su Maestro y no directamente a partir de Aristóteles, como gran parte de la crítica moderna y contemporánea lo viene haciendo.

3. El primer hito en el camino de la ruptura de la síntesis neoplatónica y aristotélica. El vaciamiento del significado metafísico y teológico del concepto de naturaleza en el De potestate regali et papali de Juan Quidort de París (1270).

En la Filosofía Política de Juan Quidort de París encontramos el primer esbozo del liberalismo político, fundamentado a partir de los siguientes principios: 1-Separación entre las dos esferas de poder, por un lado el Poder Eclesiástico y por el otro el Político (Una teoría semejante será encontrada en Dante un poco más tarde) 2-Tal separación se sustenta en la imposibilidad de ejercer jurisdicción en sentido estricto, sobre la propiedad de bienes terrestres por parte de los eclesiásticos. Los prelados solo pueden ejercer jurisdicción sobre los bienes terrenales por concesión del Emperador. Lo importante aquí consiste en subrayar que la teoría política de Quidort acerca del poder político se sustenta en el derecho de propiedad y que esta se sustenta al mismo tiempo sobre una teoría acerca de la adquisición de los bienes. Si Alberto y Tomás postulaban una Filosofía del origen del poder coherente con la lógica de sus respectivos sistemas, o lo que es lo mismo, en plena armonía con las exigencias emergentes de la síntesis neo-platónico aristotélica, Quidort en cambio deriva esa misma Filosofía a partir de un presupuesto puramente utilitario y economicista, diríamos hoy en un lenguaje más actual. En efecto, el dueño puede disponer de la cosa poseída según sus propias necesidades, sin obligación de cederla para uso común. 
Claramente se trata aquí de una escisión del derecho de propiedad respecto del origen natural de la posesión de que nos habla Aristóteles allí mismo de donde Qudidort extrajo los fundamentos de su teoría, esto es en el libro I de la Política de Aristóteles. Quidort no asume como propia la síntesis neoplatónica y aristotélica elaborada por Alberto y recibida por Tomás a cuya luz ambos teólogos leyeron el libro I de la Política del Estagirita. Esa ruptura se hace notoria en la argumentación de Quidort a partir del Cap. III de su tratado.

El De potestade regali et papali (1302/1303) de Quidort se mueve entre dos posiciones extremas: Los valdenses sostenian que la Iglesia de Dios, sus sucesores los apóstoles y los verdaderos prelados de la Iglesia de Dios permanecieron como tales hasta el papado de Silvestre I, a partir del cual con la Dontatio Constantini, comenzó a existir la Iglesia romana tal como hasta hoy permanece. Según los valdenses esa no es la verdadera Iglesia ${ }^{15}$.

Por su parte a este error Quidort contrapone el segundo, ubicado en las antípodas, el de los herodianos. Según Quidort los herodianos suponían que Cristo debía er un rey terreno. A partir de ese error se afirma luego que el Señor Papa, como representante de Cristo en la tierra posee dominio y jurisdicción sobre los bienes temporales de príncipes y varones. También dicen, y esta afirmación importa directamente a nuestro asunto, que el Papa posee este poder en proporción mayor que el príncipe, pues el Papa tiene la autoridad primaria directamente de Dios, en cuanto el príncipe la tiene mediatamente de Dios a través del Papa ${ }^{16}$.

Posteriormente Quidort define las dos esferas separándolas, radicalmente la una de la otra. Reino es el gobierno de una multitud perfecta, ordenado al bien común y ejercido por un solo individuo ${ }^{17}$. Sacerdocio en cambio, es el poder espiritual conferido por Cristo a los ministros de la Iglesia para dispensar los sacramentos a los fieles ${ }^{18}$. Esta ordenación a un solo superior la encontramos más adecuada, sostiene Quidort, entre los ministros de la Iglesia que ente los príncipes seculares, pues los ministros de la Iglesia, volcados especialmente al culto divino, pertenecen al Señor como pueblo elegido. Ya los fieles legos no reciben una determinación directa divina que los obligue, en las cosas temporales, a subordinarse bajo un solo monarca.

\footnotetext{
${ }_{15}$ QUIDORT J., De potestate regali et papali, ed. De BLEIENSTEIN F., Stuttgart, 1969, pag. 69 ${ }^{16}$ QUIDORT J, ibidem

${ }^{17}$ QUIDORT J., op. cit., pag 75

${ }^{18}$ QUIDORT J., op. cit., pag. 80
} 
Por el contrario, por un instinto natural, que proviene de Dios, están orientados a vivir en la comunidad política y para alcanzar el Bien Común, eligen jefes en cantidad según la cantidad o números de las comunidades. La subordinación pues de todos bajo un único monarca supremo en las cosas temporales no se fundamenta ni en la inclinación natural ni en el Derecho Divino, tampoco les conviene de la misma forma que a los ministros eclesiásticos ${ }^{19}$.

En Quidort pues se concreta el primer paso hacia la autonomía radical del poder político respecto del Eclesiástico. Quidort abandona los presupuestos neo-platónicos sobre los que se apoyaban Alberto y Tomás y abandona con los mismos la necesidad de la forma de gobierno mixta postulada por aquellos maestros. Para Alberto y Tomás la forma monárquica surgía por necesidad escriturística y natural al mismo tiempo. En cambio a partir del nuevo punto de vista introducido por Juan Quidirt seguirá la subordinación del orden eclesiástico al temporal o político, en los tratados políticos de Marsilio de Padua y de Thomas Hobbes. El principio de tal punto de partida puede resumirse en el siguiente axioma común a Quidort y a Dante: "ambos poderes derivan de un poder superior. Así pues, el poder secular es superior al espiritual en algunas cosas, esto es, e las cosas temporales y en estos asuntos en absoluto se encuentra subordinado al poder espiritual20" Dicha tesis solo exteriormente puede asemejarse a la del Aquinate. Con todo, la radical diferencia solo puede observarse a partir de la no menos radical transformación del concepto de ordo naturae que hemos reconstruido a la luz de la síntesis albertino- tomista. En efecto, la síntesis teológica y metafísica sobre la que sea poya respectivamente las Filosofías Políticas de Alberto magno y Tomás de Aquino fue reemplazada por el punto de vista utilitarista de Juan Quidort.

Una nueva ruptura de la síntesis albertino tomista tendría lugar en el caso de Dante. "Duos igitur fines providentia illa inenarrabilis homini proposuit intendendos: beatitudinem scilicet huius vite, que in operatione propie virtutis consistit et per terrestrem paradisum figuratur; et beatitudinem vite eterne, que consistit in fruitione divini aspectus ad quam propria virtus ascendere non potest, nisi lumine divino adiuta, que per paradisum celestem intelligi datur ${ }^{21}$ " Dante, de un modo más moderado que

${ }^{19}$ QUIDORT J., op. Cit., pags. 81-82

${ }^{20}$ QUIDORT J., op. cit., pags. 88-89

${ }^{21}$ DANTE, Monarquia, III-XV-7, en DANTE ALIGHIERI, Tute le opere, Firenze, 2007, pag. 1140 
Marsilio, pero diferenciándose claramente de Alberto y de Tomás, dirá que si bien el Papado y el Imperio se erigen sobre bases claramente diferentes ${ }^{22}$, ello no implica la subordinación de uno a otro, es decir, ni el Papa está subordinado al Emperador, ni este al $\mathrm{Papa}^{23}$, sino que ambos se deben, cada uno en su esfera a un tercero que es Dios: "Et hoc erit vel ipse Deus, in quo respectu omnis universaliter unitur, vel aliqua subtantia Deo inferior, in qua respectus superpositionis per differentiam superpositionis a simplici respectu descendens particuletur. Et sic patet quod Papa et Imperator, in quantum homines, habent reduci ad unum; in quantum vero Papa et Imperator, ad aliud: et per hoc patet ad rationem"24. También Dante como antes Quidort, a pesar de su admiración por Alberto y por Tomás, pierde de vista la síntesis entre ambos y sus consecuencias filosófico-políticas.

4. Una nueva lectura de las tesis políticas de Aristóteles: El carácter ideológico del Defensor pacis de Marsilio de Padua

Anteriormente ofrecí un cuadro esquemático de las posibles interpretaciones del texto bíblico Nulla potestas nisi a Deo. Mientras Alberto Magno y Tomás de Aquino interpretaron el texto, a fin de explicar el problema del origen del poder, dejando en un segundo plano el problema de la constitución del poder, Marsilio en cambio, exigido por las circunstancias de su tiempo, situó en primer plano precisamente la cuestión de la constitución del poder. Por entonces el problema de la constitución del poder se resolvía del modo siguiente: Dado que todo poder viene de Dios y que el Papa es el representante de Dios en la tierra, luego el poder del emperador debía ser formalmente conferido por el Papa, incluso en la categoría de un sacramento más de la Iglesia. Ello implica, por un lado la concreción práctica del axioma bíblico nulla potestas nisi a Deo, y, por el otro, la completa subordinación del poder político al religioso.

Lo que el Paduano se proponía era justificar la erección del Rey de Baviera, sin el consentimiento papal. Para ello recurrió también a Aristóteles y a las Escrituras. Vale decir, si bien lo que se proponía era liberar la Política

\footnotetext{
22 "Sicut Ecclesiae suum habet fundamentum, sic et Imperium suum. Man Ecclesiae fundamentum Cristus est; und Apostolus ad Corintios: Fundamentum aliud nemo potest ponere preter id quod positum est, quod est Cristus lesus. Ipse est petra super quam hedificata est Ecclesia. Imperii vero fundatum ius humanum est." DANTE, Monarquia, III-X-7, ed, cit.

${ }^{23}$ DANTE, Monarquía, III-XI-9, ed. cit, pags. 1133-1135 y III-XII-1, ed. cit., pag. 1135

${ }^{24}$ DANTE, Monarquia, III-XI 8 y sgts.
} 
de su subordinación a la Teología, también es verdad que lo intentó no si recurrir a una nueva fundamentación teológica. Marsilio organiza su argumentación del modo siguiente: En la primera parte de su Defensor pacis, alude a la Política de Aristóteles, en la segunda articula esas tesis a la luz del texto Sagrado y finalmente, en la tercera, extrae algunas conclusiones especialmente útiles a sus propósitos.

Marsilio comienza liberando el orden político de aquella pestífera causa de toda discordia que ni el mismo Aristóteles pudo conocer, esto es la injerencia del Poder eclesiástico en cuestiones políticas, para terminar subordinando, en una postura extrema, el Poder eclesiástico al político. Dicha operación no es arbitraria en Marsilio. En efecto, el paduano no pudo menos que admitir la existencia de una vida en el más allá donde Dios juzga, premia y castiga a cada hombre según Sus leyes. Lo que hizo fue omitir la consideración del orden natural como la mediada tangible del orden sobrenatural. Se trata, como lo he llamado en otra oportunidad, de la depotenciación del concepto de naturaleza ${ }^{25}$. Posteriormente y ya dentro de su argumentación teológica, el paduano neutralizó la acción de la Providencia y las exigencias de la Justicia Divina en el orden político, mediante el argumento siguiente: No negamos que exista una vida del más allá ni una Ley Divina, simplemente decimos que dado que ningún filósofo pudo decirnos con exactitud de qué se tratan esos conceptos, procederemos a quitarlo del horizonte de nuestras preocupaciones ${ }^{26}$. Luego, y esto es lo relevante a nuestros fines, los sacerdotes deben administrar los sacramentos y cuidar del alma de los fieles, mas subordinando su accionar al Bien Político, considerado como la más alta instancia a la que los hombres pueden aspirar. Se trata, en el caso del paduano, de un retroceso de la condición del sacerdocio al tiempo del paganismo.

5. El camino hacia la rehabilitación de la síntesis albertino-tomista. El caso de Alvaro Pelagio.

Un opositor de Marsilio fue Alvaro Pelagio (1275/1280) ${ }^{27}$. Acerca de

\footnotetext{
${ }^{25}$ Cfr. PIERPAULI J. R., Racionalidad Práctica y Filosofía Política. Los modelos de Alberto Magno y de Tomás de Aquino y su significado para la Filosofía Política actual, Buenos Aires, 2007, pags. 174 y sgts. ${ }^{26}$ Cfr. MARSILIO DE PADUA, Defensor pacis, I-IV-3, ed. de GEWIRTH A., New Cork, 2001, pags. 12-13 ${ }_{27}$ Para un estudio exhaustivo y actual de la obra de Álvaro Pais Cfr. MIETHKE J., Alvaro Pelagio e la Chiesa del suo tempo, en: Santi e Santitá. Atti del XV Convengo Internazionale, Assis, 15-16-17 de Octubre de 1987, Perugia 1989, pags. 255-293
} 
su vida no se disponen aun de datos precisos $^{28}$. En su Status et planctus ecclesiae (1332/1335) escrito en defensa del Papa Juan XII como jefe legítimo de la Iglesia y naturalmente en rechazo de las pretensiones de Pedro Corbara y del emperador Luis de Baviera, antes defendido tenazmente por Marsilio de Padua, sostiene en la línea de la tradición neo-platónica antes esbozada por Alberto Magno y recibida por Tomás de Aquino: "Et quod iurisdictionem habet universalem in tot mundo papa nedum in spiritualibus sed tempralibus, licet executionem gladii temporalis et iurisdictionis per filium suum legitimum imperatorem quum fuerit tamquam per aduocatum et defensorem Ecclesiae et per alios reges et mundi principes...." ${ }^{29}$. Aun cuando en la argumentación pelagiana permanece ausente una estructura argumental del rigor de las de Alberto y de Tomás, y de modo especial la tradición filosófico-política proveniente de Aristóteles, se observa claramente que la tesis enunciada, que termina tajantemente con la discusión acerca de la relación entre ambos poderes, el eclesiástico y el político, solo puede sustentarse en primer lugar, sobre la tradición neo-platónica aludida y en segundo lugar, en la idea derivada de esa tradición y de las Escrituras mismas, a saber que existe un solo Dios Creador y Providente, cuyo único representante en la tierra es el Papa. Al fin y al cabo también Tomás había partido de la misma idea cuando decide orientar al rey de Chipre a partir de su doble condición de fraile y de cristiano.

Un pasaje de significativa relevancia para nuestra cuestión servirá para comprender mejor la solución ofrecida por Álvaro Pelagio. Allí la tesis pelagina sigue como respuesta de la siguiente pregunta: "Agrego aquí esta pregunta Donde tubo su origen el imperio y cualquier otro dominio?"30 La primera observación que, a la pregunta, formula el autor resulta claramente en disonancia con la tradición aristotélica. Allí dice Pelagio: "No hallamos en el Derecho Natural afirmación alguna que indique que la dignidad de dominio le corresponda a persona alguna”. Pelagio se apoya en el Génesis I para afirmar que todos los hombres provienen de una misma raíz, Adán y Eva, y que los bienes materiales les fueron provistos a todos para la subsistencia, debiendo por tanto ser igualmente divididos. Sin detenerme

\footnotetext{
${ }^{28}$ Cfr. MORAIS BARBOSA J., Àlvaro Pais, Lisboa/Sao Paulo, 1992, pag. 13 y sgts.

${ }^{29}$ ALVARO PELAGIO, Status et pranto ecclesiae, ed. de Miguel Pinto de Meneses, Instituto Nacional de Investigación Científica, Lisboa, 1988, T. I., pag. 347

${ }_{30}$ ALVARO PELAGIO, Status et planctus ecclesiae, ed. De Miguel Pinto de meneses, Instituto Nacional de Investigación Científica, Lisboa, 1990, Vol. II, pags. 35-37
} 
aquí en la cuestión del derecho de propiedad en sí misma, me interesa subrayar la alusión al Derecho de Propiedad como fundamento del Poder. Se trata de la misma línea de argumentación a la que había recurrido, según vimos, Juan Quidort.

Pelagio insiste un poco más adelante en el argumento común ala tradición agustiniana de la que es deudor, a saber, que el dominio de unos hombres respecto de otros solo fue introducido luego de haber caído el hombre en el pecado original y como remedio de sus consecuencias. Curiosamente Pelagio apoya esta afirmación en la teoría aristotélica de la propiedad desarrollada en el libro I de la Política. Tal como lo habían hecho Alberto y Tomás, une a esa idea el concepto de orden elaborado por Agustín de Hiponá en la Ciudad de Dios. Con todo y pese a haber manejado casi las mismas fuentes que los doctores de la primera mitad del siglo XIII, Álvaro Pais extrae conclusiones radicalmente diferentes. Tal vez el motivo de esa discrepancia radique en la perspectiva histórico-política que condicionó la solución pelagiana a saber, la tentativa de rehabilitar la potestad papal fuertemente atacada por Marsilio de Papua. Su obstinación en denunciar la actitud cismática de Pedro Corbara lo indujo a equiparar la usurpación del poder con la soberbia de Lucifer. Pelagio cierra lapidariamente su solución: "De lo expuesto surge que el dominio al principio del mundo, y considerando las personas que lo asumieron, se siguió de la corrupta intención a saber, de la ostentación de la soberbia y de la tiranía”. Lo que importa señalar en todo caso es que Pelagio abandonó la síntesis formulada por Alberto Magno y recibida por Tomás de Aquino. Prevaleció en él la línea argumental de base neo-platónica y fue en virtud de la misma que se apoyó casi de modo unilateral en el texto bíblico para resolver una cuestión que se inscribe claramente en el ámbito de la Filosofía Política.

6. A modo de conclusión: Cinco tesis a favor de la argumentación albertino-tomista de la subordinación del poder político al eclesiástico:

Antes de ofrecer esas conclusiones debe aclararse que una vez más aquí, Alberto no aludió a los mismos problemas que su discípulo Tomás, mas preparó las bases sobre las cuales posteriormente el Aquinate pudo ofrecer nuevas soluciones.

Leo Strauss ha definido al hombre de un modo coincidente con la tradición cristiana medieval que aquí hemos expuesto sumariamente. Vale la pena citar el texto de Strauss como punto de partida de las tesis que, a mi 
juicio, sustentan la subordinación del poder político al eclesiástico o, lo que es su equivalente, de la política a la religión. Dice Strauss:

"La unidad del hombre consiste en el hecho de que él es una parte del todo, potencialmente abierto a ese todo; o, en lenguaje platónico, una parte del todo que ha visto las ideas de todas las cosas. La preocupación del hombre por su apertura al todo es la vida del espíritu. La dualidad de ser una parte y a la vez estar abierto al todo, siendo por ello, en un sentido, el mismo todo: he ahí lo que es el hombre 31 ".

En el lenguaje albertino-tomista podríamos formular la misma idea de este modo: El hombre es criatura de Dios. A diferencia de los animales posee principios naturales, inscritos en su naturaleza propia, en virtud de los cuales puede resolver las cuestiones inherentes a la vida moral y política. Mas el hombre, siguiendo la misma tradición aristotélica, no es tan solo un animal político (Primera tesis). Es político porque es racional (Segunda tesis), más aun, su racionalidad lo impulsa decididamente a trascender el horizonte filosófico para buscar en la Teología y en la religión las últimas respuestas a los problemas morales y políticos (Tercera tesis). En la perspectiva del modelo aristotélico encuentra el hombre el paradigma de la Justicia Divina, no tan solo en el texto bíblico, sino de modo inmediato en la estructura interna de la naturaleza entendida como ordo naturae (Cuarta tesis). Es conociendo la Justicia Natural que se eleva el hombre al nivel de la Justicia Divina. Si a cada nivel de orden le es correlativo un cierto bien al modo de finalidad, el Bien Común Político es fin del orden político y a su vez, análogo del Sumo Bien al que, en línea neo-platónica, consideramos principio y fin de todas las cosas (Quinta tesis).

El Poder Político no es pues el fin último de la vida político sino un instrumento al servicio del Bien Común Político. Mas dado que ese Bien Común Político está constituido por dos niveles, el material y el espiritual, se subordina el hombre al poder político en los aspectos inherentes a la subsistencia y la vida moral y política, pero permanece sujeto al Soberano Pontífice en cuanto toca a la economía de su salvación eterna. La integración de la herencia neo-platónica con la agustiniana permite pues articular una

${ }^{31}$ STRAUSS L., The problem of Socrates, en PANGLE T., The Rebirth of Classical Political Rationalism. An introduction to the Thought of Leo Strauss, Chicago-London, pag. 164 
última subordinación del Poder Político al Eclesiástico, sin perjuicio de una clara delimitación de funciones. La Filosofías Políticas que nacieron a partir de la segunda mitad del siglo XIII parecen ser variaciones de la rutprua de dicha síntesis. A su vez, la ruptura de la síntesis articulada por Alberto Magno parece constituir el hito decisivo, a los fines de circunscribir la hora de nacimiento del Estado Moderno. Pero esta perspectiva aquí ofrecida solo puede examinarse, si es que el estudio de la Filosofía Política no excluye de su horizonte los aportes ofrecidos durante el medioevo.

E-mail: josericardopierpauli@yahoo.com.ar

Recebido: março/2009

Aprovado: junho/2009 